Note

\title{
Good practice: Students present personal learning journey
}

Hans Leijenaar

Saxion University of Applied Sciences, The Netherlands.

Correspondence: $\underline{\text { h.j.jeijenaar@saxion.nl }}$

Received: 10 September 2018; Accepted: 12 December 2018; Published: 7 January 2019

Keywords: Personal reflection, creativity, storytelling, participation of audience, presentation

Note to reader: honors keywords (see introductory article of this issue) in italics in the text

\section{Introduction}

Honors students give a personal reflection on the past year at the end of the first year of the honors program 'Creativity in Finance \& Management' from the FEM (Finance, Economy \& Management, School for Finance \& Accounting) and AMA (Academy Mens \& Arbeid, School of Applied Psychology \& Human Resource Management) academies at Saxion University of Applied Sciences, The Netherlands. This is done by means of storytelling in a non-school environment (preferably a small theatre) and with an audience. The reflection involves a story about the student's personal development in the past year. The audience is brought in by the students (parents / friends / partners, etc.). The interaction with the audience turns out to be an excellent addition to the reflection moment of the student.

\section{Why this good practice?}

It is a big challenge for honors students to reflect in depth on their own personal development of the past year without using a portfolio or any other method of written recording. Such a reflection is very important in honors programs. In addition, most students in the university are 'flooded' with portfolios, and there are only a few students who are happy to make such a written portfolio. Furthermore, the people in the audience who are close to the student prevent the student from giving a socially desirable presentation.

\section{Target group and target group size}

Participants are first-year honors students of the extra-curricular honors program 'Creativity in Finance \& Management.' These students are second-year students in the regular bachelor program of four years. The honors program only starts after the foundation year. The size of this activity is 3 hours for the execution. The preparation time varies per student and is about 8 hours. If the students want to take this assignment, they will have to do the 
complete first year of the honors program (HP). The complete three-year honors program has the size of $30 \mathrm{ECs}$ (which are virtual credits because the program is extra-curricular and comes on top of the regular program) divided over three years.

\section{Educational design (structure)}

At the end of year one of the honors program, students meet in a small theatre (Vestzaktheater) in the town of Enschede, The Netherlands, in the evening. This is a small, intimate setting (small room, 50 seats). A session usually involves about eight to 10 students, which is the maximum for one evening. The student brings along at least two people who know him / her well and / or are close to him / her (parents, boyfriend / girlfriend, etc.).

The intention is that students tell the audience about their learning journey of the first honors year: What did the student learn from this? What has he / she encountered, what has he / she overcome, what does he / she want to work on? The student does this individually using storytelling. There are only a few guidelines for the student:

1. It has to be a personal story

2. They have to take an object with them that symbolizes their development and incorporate this object in their story

3. It has to be creative

4. There must be emotion in it

5. The audience (including the people who do not know the student) must get a good, accurate picture of the student.

At the end of the story, called the 'learning journey,' the people in the audience can ask questions. The teacher often starts by asking the persons closest to the student if they recognize the student in the story. Then, other people from the audience can ask questions. The evening is concluded informally with a snack and a drink at the bar of the theatre.

\section{Student assessment}

The student and the lecturer give an assessment where the following aspects are taken into account:

- Creativity of the presentation

- Use of the chosen object and the link with personal development

- Reflection in presentation on own development

- Reflective attitude in question / answer-part

They can grade with insufficient / sufficient / good / excellent. Students assess themselves and, in most cases, the teacher will agree on the self-given grade.

\section{Experiences}

Until now, these meetings have been held for four years (so four times) at the end of the first honors year. It is an amazing event. The students generally find it very exciting, and they see the fun in it. The event quickly turns personal, and everyone is engaged - especially the people who are close to the student. It often generates a lot of (positive) emotions and creates an enormous bond. The audience that is brought in always reacts enthusiastically and parents are especially impressed by both the teaching method and the presentation of their son / daughter. The interaction with the audience is an excellent addition to this reflective moment of the student; not only the people who are closest to the student can give a reaction, but the rest of the audience will ask questions as well, showing genuine 
interest.

\section{Time requirement for teachers}

Students have to do the main part of the 'work,' so the time necessary for the teacher is very limited. The teacher provides a good introduction of the assignment, makes a reservation for the theatre, and supervises the evening.

\section{Tips for teachers}

Give students free rein as much as possible; do not prepare anything. Check whether students are indeed preparing (just ask; they do not have to show anything) and ask if they will take people with them (this is very important!). Let it happen that evening, let it originate, and let it grow. As a teacher, you will talk in between the presentations, you will give the audience the opportunity to participate, and you will monitor time. In order to get the public acquainted, it is nice to do some 'exercises' with the audience first to create a confidential atmosphere. For example, everyone goes on stage and makes a row based on height or on the basis of age (even better: you are not allowed to talk!) - or, walk around, shake hands with someone you do not know, and introduce yourself in one minute.

\section{Tips for students}

The teacher gives the following advice to his students: 'Let's really see what you stand for and who you are. Link the object that you take with you to your own development (often as a metaphor). Be surprising, show emotion, and do not be afraid.'

\section{Transfer to other programs}

This approach is very suitable for other honors programs, but it does require a somewhat greater ability of the student for self-reflection. It is important that, in the first honors year, confidence has grown so that the student is not afraid to step out of his / her comfort zone and that the student has shown more of himself or herself and has been able to practice with all kinds of educational methods. What can be learned from this and can be applied to regular education is that all students, including the students who show no interest in selfreflection or have difficulties in writing a thorough self-reflective report, are particularly capable of reflecting in this way, once they are given the freedom and coached in the right way.

\section{References, additional information and relation with Circle of Talent Development}

\section{$\underline{\text { Relation with Circle of Talent Development }}$}

In the introductory article of this issue of JEHC, the 'Circle of Talent Development' has been described. Based on interviews with forty honors students and literature about honors programs, it reflects relevant activities of students regarding the development of their talents in an honors program. The author of this note has been asked to score the good practice in relation to the activities in the Circle of Talent Development. The meaning of the scores is: + = somewhat important; ++ = moderately important; +++ = very important; $-=$ not applicable or irrelevant. The scores are intended to illustrate the strengths of a good practice for the reader. 
Figure 1: Circle of Talent Development in relation with the good practice 'Students present personal learning journey' with the teacher's scores

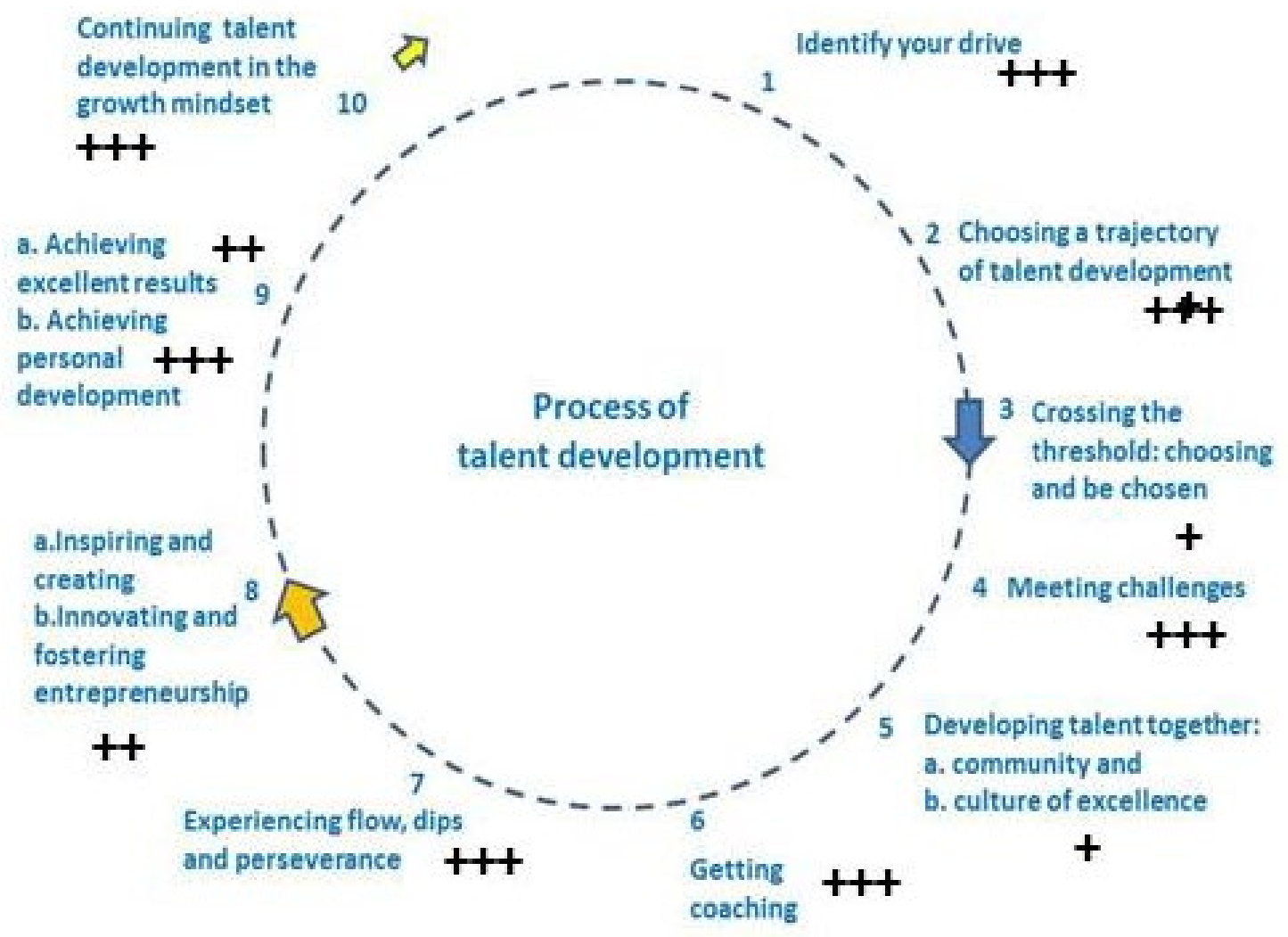

Question to the teacher: What makes this good practice attractive for other teachers? The teacher of this practice argues: 'It is a relatively simple and unique way to give students the opportunity to reflect in a group. This reflection is not in a way and a format that is described by the teacher, but it is a reflection from the heart. The amount of effort the teacher has to put in for this final event is limited, but the results (and impact) are high.' 